\title{
Embraer diversifica projetos na área militar: o novo cargueiro C-390
}

\author{
Armando Dalla Costa* \\ Elson Rodrigo de Souza-Santos**
}

RESUMO - Em 2007, durante a feira de defesa Latin American Aero and Defence - LADD, a Embraer confirmou os rumores de mercado sobre a concepção do projeto de um novo modelo de avião. O cargueiro C-390 representa um marco para a companhia ao entrar no concorrido mercado de transportes militares da classe de 20 toneladas, com concorrentes como a norteamericana Lockheed Martin, a europeia AirBus e a ucraniana Antonov, mas com um modelo de menores custos (aquisição e operacional) e com amplo uso de componentes da família de jatos regionais e tecnologias conhecidas, que deve realizar seu primeiro voo em 2015. A meta é explorar um mercado militar e civil de mais de 700 aeronaves nas próximas décadas, inicialmente conseguindo pedidos firmes de cerca de 50 aeronaves, suficientes para viabilizar economicamente o projeto. Demonstrar como isto foi possível é o objetivo principal deste artigo.

Palavras-chave: Indústria aeroespacial. Embraer. C-390.

\section{INTRODUÇÃO}

No ano de 2007, durante a feira de defesa Latin American Aero and Defence - LADD, realizada no Rio de Janeiro, a Embraer confirmou rumores de mercado de que estaria estudando a possibilidade de um projeto de avião de transporte militar para 19 toneladas, pré-denominado Embraer C-390 (FOLHA ONLINE, 2007). Segundo Luiz Carlos Aguiar, vice-presidente executivo para o mercado de defesa e governo da Embraer, o objetivo da companhia era oferecer uma aeronave de transporte inovadora, de menor custo de operação e aquisição por utilizar tecnologias desenvolvidas para a linha civil, especialmente dos jatos regionais 170/190. O mercado vislumbrado pela empresa são os países que precisam renovar a sua frota de transportadores militares médios, mas não encontram no mercado opções a preços atrativos, e a alternativa de aeronaves usadas é dificultada pela escassez de modelos disponíveis, além do mercado civil de transporte de cargas ser um segmento a ser atingido devido a escassez de modelos de cargueiros "puros" a custos competitivos em relação a aeronaves de passageiros adaptadas para curtas e médias distâncias.

Dessa forma, o objetivo do trabalho é dar prosseguimento ao estudo iniciado no arti-

\footnotetext{
* Doutor em histórica econômica pela Universidade de Paris III. É professor do Departamento de Economia e do Programa de Pós-Graduação em Desenvolvimento Econômico da Universidade Federal do Paraná. Endereço eletrônico: ajdcosta@ufpr.br.

** Mestrando do Programa de Pós-Graduação em Desenvolvimento Econômico pela Universidade Federal do Paraná. É bolsista do CNPq. Endereço eletrônico: elson129@gmail.com.
} 
go sobre a Embraer de Dalla Costa e Souza-Santos (2010), mas transferindo o foco da empresa para o projeto de cargueiro C-390, que inova na concepção de negócio da companhia no tipo de produto e lança a Embraer para competir em novos mercados. Assim, o trabalho está articulado em duas partes. Uma que apresenta o que é a Embraer atualmente e, outra, que foca no que é o projeto de cargueiro militar C-390.

\section{EMBRAER E A INDÚSTRIA AERONÁUTICA}

A Embraer - Empresa Brasileira de Aeronáutica S.A. - é a terceira maior empresa aeronáutica produtora de aeronaves civis do mundo, atrás apenas da norte-americana Boeing e da europeia AirBus. A história da empresa remonta há mais de 40 anos, em que produziu cerca de 5.000 aviões operados em 88 países. Nos anos de 1999 e 2001, a Embraer foi a maior exportadora brasileira e a segunda maior nos anos de 2002, 2003 e 2004. A partir de 2004 nasceu a nova família de jatos regionais, com as plataformas Embraer 170/190 obtendo sucesso no mercado internacional de aviação regional (EMBRAER, 2010). Ao observar os números no triênio 2007-2009 é evidente que a companhia está em expansão e, mesmo com a crise mundial de 2008/2009 que afetou o mercado de aviação civil e os planos de ampliação e renovação de frotas, continua sólida e enfrentou bem as adversidades (ver Tabela 1).

TABELA 1 - EMBRAER EM NÚMEROS: 2007-2009

\begin{tabular}{lrrr}
\hline & $\mathbf{2 0 0 7}$ & $\mathbf{2 0 0 8}$ & $\mathbf{2 0 0 9}$ \\
\hline Receita líquida (em R\$ milhões) & 9.994 & 11.747 & 10.813 \\
Lucro líquido (em R\$ milhões) & 1.185 & 429 & 895 \\
Entrega de aeronaves & 169 & 204 & 244 \\
Ordens firmes (em US\$ bilhões) & 19 & 21 & 17 \\
Investimento em P\&D (em R\$ milhões) & 413 & 482 & 353 \\
Ativo total (em R\$ milhões) & 15.476 & 21.499 & 15.946 \\
Patrimônio líquido (em R\$ milhões) & 4.638 & 5.971 & 5.021 \\
Empregados & 23.734 & 23.509 & 16.853 \\
\hline
\end{tabular}

FONTE: Embraer (2010b) e quadro construído pelos autores.

A trajetória da Embraer não foi linear desde a sua fundação em 1969. Para Dalla Costa e Souza-Santos (2010), a fundação da companhia em 1969, como estatal de capital misto, cristalizava o projeto nacional de desenvolvimento e domínio da tecnologia aeroespacial originada na década de 1930. Entretanto, como observam Marques e Oliveira (2009), os projetos da empresa visavam consolidar e impulsionar o domínio de tecnologias militares tendo como principal cliente a Força Aérea Brasileira - FAB. De um lado, isso permitiu o acúmulo de conhecimento e tecnologias essenciais para manter a companhia produtiva, mas de outro deixou a Embraer presa aos objetivos da política de defesa nacional e às encomendas do Estado.

$\mathrm{Na}$ década de 1980, quando a crise econômica e as encomendas governamentais es- 
casseavam, criaram um ambiente favorável a mudança de foco dos negócios da companhia, e simpático a privatização acompanhando a mudança, a abertura e a redução do tamanho do Estado. Assim, Goldstein (2002) observa que no começo dos anos 1990 as administrações Collor e Franco promovem a reestruturação e preparação da Embraer para ser privatizada, incluindo o adiamento de projetos como o jato regional ERJ 145, que representava a mudança de foco da companhia e busca por novos mercados. A privatização ocorreu no fim de 1994, sendo que o controle da companhia permaneceu em mãos nacionais através dos fundos de pensão Previ (20\%), Sistel (20\%) e Companhia Bozano, Simonsen (20\%), além de sócios minoritários como a EADS - France e Dassault e a golden share do Estado brasileiro, a fim de vetar negócios que potencialmente prejudicassem a segurança nacional.

A partir da privatização, a Embraer passou a focar na consolidação da nova concepção de estratégia de negócio tendo como meta o mercado civil, especificamente o segmento de jatos regionais, pouco explorado pelas outras empresas aeronáuticas, e tendo como grande competidora a canadense Bombardier. Outro forte motivo para essa tomada de decisão, como ressalta Goldstein (2002), foi o fato de o segmento de aviação crescer cerca de 50\% entre 1998 e 1999, especialmente no principal mercado, que é norte-americano. A Embraer conseguiu se aproveitar da oportunidade e, como consequência, as exportações de jatos regionais totalizavam $90 \%$ do total, tendo como carro-chefe o ERJ 145, sendo mais tarde consolidadas pela família 170/190.

Como parte da nova forma de se inserir no mercado, a companhia dividiu suas atividades em quatro áreas: aviação comercial ( $58 \%$ da receita no terceiro trimestre de 2010); executiva (19\%); defesa (7\%); e serviços aeronáuticos e outros (16\%) (EMBRAER, 2010). Em termos de receita, a companhia tem uma concentração elevada nos segmentos de aviação comercial (58\%), que, apesar de ser o carro-chefe dos negócios, possui um caráter cíclico diretamente relacionado ao desempenho da economia mundial, representando um potencial risco para a solidez e competitividade no longo prazo.

\section{PROJETO DO CARGUEIRO C-390}

Considerando a elevada dependência e volatilidade do mercado civil de aviação comercial, a Embraer, nos últimos anos, passou a ampliar a gama de produtos das outras áreas, levando à introdução de uma nova linha de aeronaves executivas Phenon, Legacy e Lineage, fazendo frente a concorrentes consolidadas no setor, tais como a francesa Dassault e a japonesa Honda. $\mathrm{Na}$ área de defesa, a empresa começou a ampliar a sua participação proporcional reduzida das décadas de 1990/2000 após a privatização, passando a atender as demandas das 
forças armadas brasileiras e de outros países. Para isso o projeto de C-390 inova por ser uma aeronave nova para atender a demanda nascente de renovação/ampliação da frota de aviões de transporte militar médio de países com influência ocidental, anteriormente restritos a opção do modelo norte-americano Lockheed C-130 Hercules e suas evoluções/derivações desde a década de 1950.

\subsection{NICHO DE MERCADO E OPORTUNIDADES}

A identificação de oportunidades de crescimento no mercado aeronáutico militar para a Embraer esbarra em quatro fatores: i) dificuldade em obter parceiros e fornecedores externos, pois muitas das tecnologias de ponta na área militar não estão a venda ou sofrem fortes restrições dos Estados nacionais como parte da política de segurança nacional; ii) o desenvolvimento de tecnologias de fronteira é alto e os riscos elevados; iii) falta de interesse e respaldo financeiro através do financiamento de pesquisa e desenvolvimento e aquisições por parte do Estado e forças armadas brasileiras; e iv) estratégia agressiva de protecionismo e influência política militar dos principais países produtores de equipamentos militares, permitindo vantagens para suas empresas e produtos em concorrências internacionais.

Nesse cenário, a Embraer adotou a estratégia de entrar em nichos de mercado que fossem pouco explorados e necessitassem de produtos diferenciados que pudessem ser produzidos com tecnologias comercializáveis e de poucas restrições. Dalla Costa e Souza-Santos (2010) citam como exemplo os projetos do Super Tucano e dos aviões de inteligência baseados na plataforma do jato regional ERJ 145, ambos nascidos da necessidade do Estado para a implantação do projeto SIPAM/SIVAM (Sistema de Proteção da Amazônia/Sistema de Vigilância da Amazônia), constituindo um conjunto de radares, satélites e sistemas de sensoriamento remoto da região amazônica. De um lado, a aquisição de aviões de inteligência era parte dos planos da FAB de criar um sistema de inteligência capaz de ser colocado em pé de igualdade com a estrutura encontrada em países de primeiro mundo; para isso, a Embraer formulou o projeto de transformar os ERJ 145 em bases de inteligência móveis, mais baratos que os usados pela OTAN e mais flexíveis devido ao menor tamanho, tendo como principal parceira a sueca Saab e despertando o interesse de Grécia, México e Índia. De outro, o Super Tucano foi um reprojeto do Tucano, em busca de dar maior capacidade de ataque ao solo e de antiguerrilha, especialmente para ser usado no SIVAM, sendo ele um avião com maior poder de fogo, alcance e resistência. Único em sua classe, por ser muito mais um avião de combate do que de treinamento quando comparado a modelos semelhantes, suas vendas foram fechadas com Chile, Colômbia, Equador, Canadá e República Dominicana, chegando a despertar interesse do maior 
mercado do mundo para equipamentos de defesa, os Estados Unidos.

No caso do cargueiro militar C-390, segundo o diretor de mercado para a área de defesa, Fernando Ikedo, a ideia nasceu em 2005 como um estudo interno visando produzir um cargueiro militar de médio porte. Na primeira etapa, quebrou-se o mercado de aeronaves militares em quatro faixas considerando a capacidade de carga: leves (até 5 toneladas); médias (de 5 a 10); pesados (de 10 a 20); e superpesados (mais de 20), sendo selecionado o estudo para oferecer aeronaves na faixa de 5 a 20 toneladas, por ser essa a mais numerosa do mercado, constituindo cerca de 2,8 mil aeronaves, excluindo China, Coreia do Norte e Irã por razões políticas. O passo seguinte foi considerar os cargueiros com mais de 25 anos de uso que deviam ser substituídos nos próximos anos, chegando a 1,6 mil. Retirando desse total o mercado dos grandes produtores (Estados Unidos, Ucrânia e Rússia) e os países que equacionaram o problema do transporte militar, sobra um mercado potencial de 700 unidades (SALLES, 2011).

A maior demanda seria por um transportador na faixa de 20 toneladas e, na avaliação de Ikedo, os principais competidores seriam: o europeu A400M fabricado pela divisão militar da AirBus; os modelos norte-americanos C-130J e C-130 modernizados da Lockheed Martin; o italiano C-27J da Alenia; e o ucraniano An-72/74 da Antonov. Outros modelos que podem ser competidores em potencial: o Multi-Role Transport Aircraft (MRTA) nascido da parceria entre Rússia e Índia, com previsão de primeiro voo para 2016; o chinês Shaanxi Y-9, que teve o primeiro modelo entregue a força aérea chinesa em 2009, além de poder se considerar o japonês Kawasaki C-2, que voou pela primeira vez em 2010, desenvolvido para a Força Aérea de Autodefesa do Japão, que devido a restrições legais não pode ser exportado como material de defesa mas que vislumbra uma versão para o mercado civil.

Cabe ressaltar que além do mercado militar considerado pela Embraer são necessários outros fatores para avaliação do mercado potencial do projeto C-390. Primeiro: devido a fatores técnicos e políticos, os países (ou os tradicionais operadores de equipamentos) ocidentais tendem a optar por modelos também ocidentais, apesar de fabricantes russos, ucranianos e chineses buscarem certificar as aeronaves no ocidente e utilizar componentes-chaves dessa região, como motores que facilitem a manutenção, visando esse mercado. Segundo: mesmo aeronaves com capacidades de transporte semelhantes podem ter funções muito diferentes e operarem em conjunto, como é o caso dos modelos C-130 e C-27, que operam em conjunto nas forças armadas norte-americanas. Terceiro: fatores políticos e de influência afetam a opção de países por determinado tipo de aeronave e sua origem, beneficiando ou prejudicando determinado modelo; por exemplo, a grande dificuldade de aeronaves europeias em serem adquiridas pelas forças armadas norte-americanas, evidenciada pela vitória da Boeing sobre a AirBus e Antonov 
para fornecer aviões de abastecimento à força aérea norte-americana (AEROMAGAZINE, 2011). Por fim, o mercado civil não pode ser descartado, já que um transportador de 20 toneladas teria vantagens nas operações de curtas e médias distâncias, operando em aeroportos menos equipados ou por empresas como FedEx, DHL e Correios.

\subsection{CONCEPÇÃO DO PROJETO}

Após identificar o mercado potencial para um transportador militar de 20 toneladas, a Embraer passou as traçar as diretrizes técnicas do projeto e a garantir vendas para pagar o custo de desenvolvimento. A concepção inicial do projeto foi apresentada em 2007 na LAAD realizada no Rio de Janeiro, pré-denominado de C-390, que seria um transportador militar médio capaz de transportar cerca de 20 toneladas, utilizando tecnologias existentes, comercializáveis e com elevada comutabilidade com os sistemas e componentes utilizados na aviação civil e nos modelos de jatos regionais da família E-Jet (E-170, E-175, E-190 e E-195), visando baixo custo de operação e aquisição frente aos demais concorrentes.

Entretanto, a concepção apresentada na LAAD em 2007 era apenas uma prévia de um projeto que necessitava de uma longa estrada de desenvolvimento, mas como equipamento militar era essencial que existisse apoio do Estado e que a FAB auxiliasse nos requisitos técnicos e garantisse a aquisição das primeiras unidades para viabilidade técnica e financeira. Sobre a importância da FAB para o projeto, Ikedo afirmou (SALLES, 2011): “A FAB precisava de um avião que fizesse muita coisa além de transporte de carga e de paraquedistas, ele deveria também combater incêndios, realizar missões humanitárias, transportar feridos, transferir e receber combustível de outras aeronaves, etc.".

As exigências da FAB para as diretrizes técnicas do projeto não eram novidades em relação as aplicações possíveis para um cargueiro militar. Temos como exemplo o norte-americano C-130, que possui cerca de 40 versões por ser uma ótima plataforma para as mais diversas missões ligadas ao transporte, como patrulha marítima e combate a incêndios. A FAB entra como uma das clientes em potencial do projeto, pois precisa renovar a atual frota de transporte, formada por C-130 antigos, nos próximos anos, sendo que o possível substituto poderia ser a versão atual do C-130 ou do A400M. Porém, seriam grandes os custos de aquisição e operação, sem benefícios para a indústria nacional, na medida que seriam de 20 a 30 unidades ao longo das décadas. Assim, na LAAD de 2009, depois de dois anos de negociações, Ikedo ressaltou que o contrato entre Embraer e FAB foi assinado para o desenvolvimento e construção de dois protótipos, mas que o contrato de aquisição seria assinado só posteriormente.

Meses depois, na Feira de Farnborough, na Inglaterra, considerada uma das mais im- 
portantes na área de aviação, a Embraer anunciou ter recebido a intenção formal de compra de 28 aeronaves pela FAB, seguida em quantidade por Colômbia (12), Argentina (6), Chile (6), Portugal (6) e República Tcheca (2). Entretanto, como observa Ikedo, a intenção de compra manifestada por esses países envolve negociações complexas e simultâneas em três níveis distintos: governo-governo, força aérea-força aérea e, finalmente, Indústria-Indústria, esta última relacionada a participação de empresas locais e ao auxílio na definição das características técnicas do produto (SALLES, 2011). Há também a primeira venda para o mercado civil, tendo como cliente os Correios, que almejam ter a sua própria frota de transporte, inicialmente assumindo o compromisso de cinco unidades, podendo atingir de 20 a 30 (FOLHA ONLINE, 2010).

Atualmente, o C-390 está em fase final de definição do design, e na sede da Embraer já se encontra o mock-up (modelo 3D em escala real), feito em madeira, com o corpo do avião, que representa perfeitamente o exterior e o interior da fuselagem, sendo útil para o teste e para experimentar as dificuldades de acomodar diversos tipos de cargas, como veículos de combate a incêndio e blindados. A companhia também está refinando as características técnicas, como elevar a capacidade de carga de 19 para 23 toneladas e definir os principais fornecedores e equipamentos utilizados, como a marca e o modelo de turbina. Nos próximos anos ocorrerá o desenvolvimento da aeronave em si, levando ao primeiro protótipo por volta de 2015, ainda incorporando inovações e mudanças para preencher novas necessidades dos clientes. A partir de então, o modelo C-390 passará pela fase de homologação e certificação, para poder atingir tanto o mercado militar quanto o civil.

\section{CONSIDERAÇÕES FINAIS}

O cargueiro C-390 da Embraer representa a busca da companhia por explorar novos mercados e aprofundar o envolvimento com o militar, como forma de minimizar a volatilidade do segmento de mercado civil, líder dos negócios da companhia, mas também uma característica comum nos projetos da Embraer: buscar nichos que sofram pouca competição das grandes empresas aeronáuticas mundiais e que apresentem elevado potencial de crescimento, oferecendo produtos inovadores, os quais devem ter as primeiras unidades voando por volta de 2015, fabricados com tecnologias conhecidas, de baixos riscos e custos, objetivando um diferencial entre os potenciais concorrentes.

Como se trata de um projeto militar, a empresa busca o apoio do Estado através da $\mathrm{FAB}$, que auxilia nos requisitos técnicos e nas primeiras encomendas para viabilizá-lo. Ao mesmo tempo, busca governos e parceiros interessados em dividir riscos ou serem fornecedores, além de forças aéreas interessadas nesse tipo de equipamento, como Colômbia, Argentina, 
Chile, Portugal e República Checa, seguidas de clientes civis que têm interesse em adquirir cargueiros puros para as suas atividades, caso do possível primeiro cliente civil, os Correios, que pretendem manter a sua empresa de transporte aéreos, e também o FedEx e a DHL. Até o momento, totaliza-se a intenção de compra de mais de 50 unidades, que viabilizam economicamente ainda mais o projeto.

O cargueiro C-390 é diferenciado mesmo frente aos concorrentes mais diretos, especialmente ao norte-americano C-130 e ao europeu A400M, tanto em custos quanto facilidade de manutenção, pelo motivo de trazer consigo muito da lógica de projetos civis de aeronaves. Rumores inclusive surgem de que os Estados Unidos e a França poderiam ser clientes em potencial para o C-390, mas com tal feito esbarrando em fatores políticos e estratégicos que devem ser equacionados pelo governo brasileiro, dentro de uma relação Estado-Estado.

\section{REFERÊNCIAS}

BOEING vence a batalha do KC-X. Disponível em: < http://aeromagazine.uol.com.br/noticia/boeing-vence-batalha-do-kc-x77752>. Acesso em: 11/3/2011.

CONHEÇA a Embraer. Disponível em: < http://www.embraer.com/pt-BR/ConhecaEmbraer/EmbraerNumeros/Paginas/Home.aspx >. Acesso em: 21/8/2010.

CORREIOS querem criar empresa própria de aviação. Disponível em: < http://www1.folha. uol.com.br/folha/dinheiro/ult91u323718.shtml >. Acesso em: 10/3/2011.

DALLA COSTA, A.; SOUZA-SANTOS, E. R. Embraer, história, desenvolvimento de tecnologia e a área de defesa. Economia \& Tecnologia, Curitiba, ano 6, v. 22, p. 173-183, 2010.

EMBRAER confirma estudo para fabricar jato de transporte militar. Disponível em: < http:// www1.folha.uol.com.br/folha/dinheiro/ult91u116258.shtml >. Acesso em: 10/3/2011.

EMBRAER: relatório anual 2009. Disponível em: < http://www.embraer.com.br/relatorios_ anuais/relatorio_2009/portugues/index.html >. Acesso em: 20/8/2010.

EMBRAER revela novidades sobre o programa KC390. Disponível em: < http://www.alide. com.br/joomla/index.php/capa/75-extra/2103-embraer-revela-novidades-sobre-o-programa-kc390 >. Acesso em: 11/3/2011.

GOLDSTEIN, A. Embraer: from national champion to global player. Cepal Review, n. 77, p. 97 - 115, aug. 2002.

MARQUES, R. A.; OLIVEIRA, L. G. Sectorial system of innovation in Brazil: reflections about the acumulation of technologial capabilities in the aeronautic sector. In: MALERBA, F.; MANI, S. (Org.). Sectorial systems of innovation and production in development countries: actors, structure and evolution. Northampton: Edward Elgar Publishing, 2009, p. 156 - 207. 